\title{
Diversity of influenza-like illness etiology in Polish Armed Forces in influenza epidemic season
}

\author{
Janusz Kocik ${ }^{1 凶}$, Marcin Niemcewicz르, Izabela Winnicka ${ }^{1}$, Aleksander Michalski², \\ Agata Bielawska-Drózd², Marcin Kołodziej², Justyna Joniec², Piotr Cieślik², Grzegorz Graniak², \\ Tomasz Mirski², Jerzy Gaweł2, Anna Bielecka-Oder1, Leszek Kubiak ${ }^{1}$ and Kevin Russell ${ }^{3}$
}

'Department of Epidemiology, General Karol Kaczkowski Military Institute of Hygiene and Epidemiology, Warsaw, Poland; ${ }^{2}$ Biological Threat Identification and Countermeasure Center of General Karol Kaczkowski Military Institute of Hygiene and Epidemiology, Puławy, Poland; 3 United States Armed Forces Health Surveillance Center, Silver Spring (AFHSC), Maryland, USA

The aim of this study was to conduct an epidemiological and laboratory surveillance of Influenza-Like Illnesses (ILI) in Polish Armed Forces, civilian military personnel and their families in 2011/2012 epidemic season, under the United States Department of Defense-Global Emerging Infections Surveillance and Response System (DoDGEIS). ILI incidence data were analyzed in relation to age, gender, patient category as well as pathogen patterns. Multiple viral, bacterial and viral-bacterial co-infections were identified. Nose and throat swabs of active duty soldiers in the homeland country and in the NATO peacekeeping forces KFOR (Kosovo Force), as well as members of their families were tested for the presence of viral and bacterial pathogens. From October 2011 to May 2012, 416 specimens from ILI symptoms patients were collected and analyzed for the presence of viral and bacterial pathogens. Among viruses, coronavirus was the most commonly detected. In the case of bacterial infections, the most common pathogen was Staphylococcus aureus.

Key words: Influenza, ILI, surveillance, Polish Army

Received: 30 May, 2014; revised: 12 August, 2014; accepted: 26 August, 2014; available on-line: 08 September, 2014

\section{INTRODUCTION}

Influenza-Like-Illnesses (ILI) include all cases of upper and/or lower respiratory tract diseases emerging seasonally on a large scale and caused by viruses or bacteria (Leo et al., 2010; Cui et al., 2012). Outbreaks of ILI result in significant morbidity in the whole population and mortality in certain high-risk patient groups (Harrison et al., 1998). Neglected and/or improperly treated patients may also develop severe complications. Military population is a high-risk group due to close living conditions, psychological stress and difficulty in maintaining personal hygiene under strict training conditions. Military personnel who live and work at a military base remain within its confines. Professional interactions among the personnel in a contingent facilitate face-to-face contacts between individuals from different military units. Moreover, selected military personnel may have contacts with families of local inhabitants. These factors may facilitate disease transmission.
As the air-borne transmission of pathogens to military population may decrease combat capabilities (Bombardt \& Brown 2003), the Department of Defense-Global Emerging Infections Surveillance and Response System (DoD-GEIS) has been established. The DoD-GEIS mission is to support and coordinate DoD global surveillance of epidemiological data and microbial agents causing serious diseases in military populations (such as ILI, sexually transmitted diseases, food-borne diseases, and tick-borne diseases). Respiratory diseases are one of the top priorities for DoD-GEIS activity. The DoD-GEIS provides professional assistance to several DoD-GEIS partnering organizations in the world, including the Military Institute of Hygiene and Epidemiology in Poland, in order to complete an epidemiological and laboratory investigation of ILI cases among soldiers.

\section{MATERIALS AND METHODS}

Study population and clinical samples. Military personnel, including active troops, military retirees and civilian personnel, working in military units, as well as their families were enrolled in this study. The population studied lived or was deployed in Lubelskie and Masovian Voivodeships in Poland and in Camp Bondsteel in Kosovo (KFOR). Patients manifesting common influenza symptoms as: fever $\geq 38^{\circ} \mathrm{C}$, cough, sore throat, runny or stuffy nose, headaches and/or body aches, chills, nausea, vomiting and diarrhea were selected during consultations by military physicians between October 2011 and May 2012. Aside from regular medical examination, participation in surveillance program was offered to patients.

Health Questionnaire and Application Study Forms were filled for each consenting patient. Personal, disease manifestation, treatment, vaccination data and putative exposure conditions were comprised in the questionnaires. Subsequently, clinical material was collected from the nasopharynx with sterile swabs, then

\section{e-mail: jkocik@wihe.waw.pl}

Abbreviations: BTICC, Biological Threat Identification and Countermeasure Center; cDNA, complementary deoxyribonucleic acid; $\mathrm{Cl}_{95 \%}, 95 \%$ confidence interval; DoD-GEIS, Department of DefenseGlobal Emerging Infections Surveillance and Response System; EUCAST, European Committee on Antimicrobial Susceptibility Testing; ILI, Influenza-like illness; KFOR, Kosovo Force; NATO, North Atlantic Treaty Organization; MSSA, methicillin-sensitive Staphylococcus aureus; MRSA, methicillin-resistant Staphylococcus aureus; PCR, polymerase chain reaction; WHO, World Health Organization. 
stored in preserving medium separately for bacteria and viruses and was shipped to the BTICC laboratory.

Virus nucleic acids detection. QIAamp Viral RNA Mini Kit (Qiagen, Germany) was used for nucleic acids isolation from the nasopharyngeal swabs. Reverse transcription was performed using iScript cDNA Synthesis Kit (Bio-Rad). The obtained cDNA was amplified using RV Panel Amplification (Seegene, South Korea) containing a set of primer pairs specific for viral respiratory pathogens according to the manufacturer's instructions. The samples were tested in a CFX96 Real-Time PCR Detection System (Bio-Rad) by nested real-time PCR using an RV Panel Real-Time Detection kit (Seegene, South Korea). Simultaneous identification was carried out to identify the following pathogens: influenza A viruses, influenza B virus, respiratory syncytial virus $\mathrm{A} / \mathrm{B}$, human metapneumovirus, human adenovirus $\mathrm{A} / \mathrm{B} / \mathrm{C} / \mathrm{D} / \mathrm{E} / \mathrm{F}$, coronavirus 229E/NL63/OC43/HKU1, rhinovirus/enterovirus, bocavirus $1 / 2 / 3 / 4$ and parainfluenza virus $1 / 2 / 3 / 4$. Influenza A positive samples were subtyped using a FluA Real-Time Subtyping kit (Seegene, South Korea) which allows identifying the following influenza A subtypes: 2009 pandemic H1N1, human flu H3N2, and human flu H1N1.

Bacterial culture. Classical culture methods with selective media were used for bacteria identification. Specific Biochemical Test Panels and semi-automated system Mini-API (bio-Merieux, France) were used to identify bacteria species. The Disk Diffusion Method with Müller-Hinton Agar Medium (Graso, Poland) were used for testing antimicrobial susceptibility according to the EUCAST (The European Committee on Antimicrobial Susceptibility Testing) recommendations (EUCAST, 2012).

\section{RESULTS}

Four-hundred and sixteen specimens from patients with ILI symptoms were collected between October 2011 and May 2012. Seventeen samples were excluded from the study due to a lack of diagnostic validity. Among 399 samples analyzed for viral pathogens and 249 for bacterial pathogens, 40\% (162/399) and 36\% $(89 / 249)$ respectively, were positive.

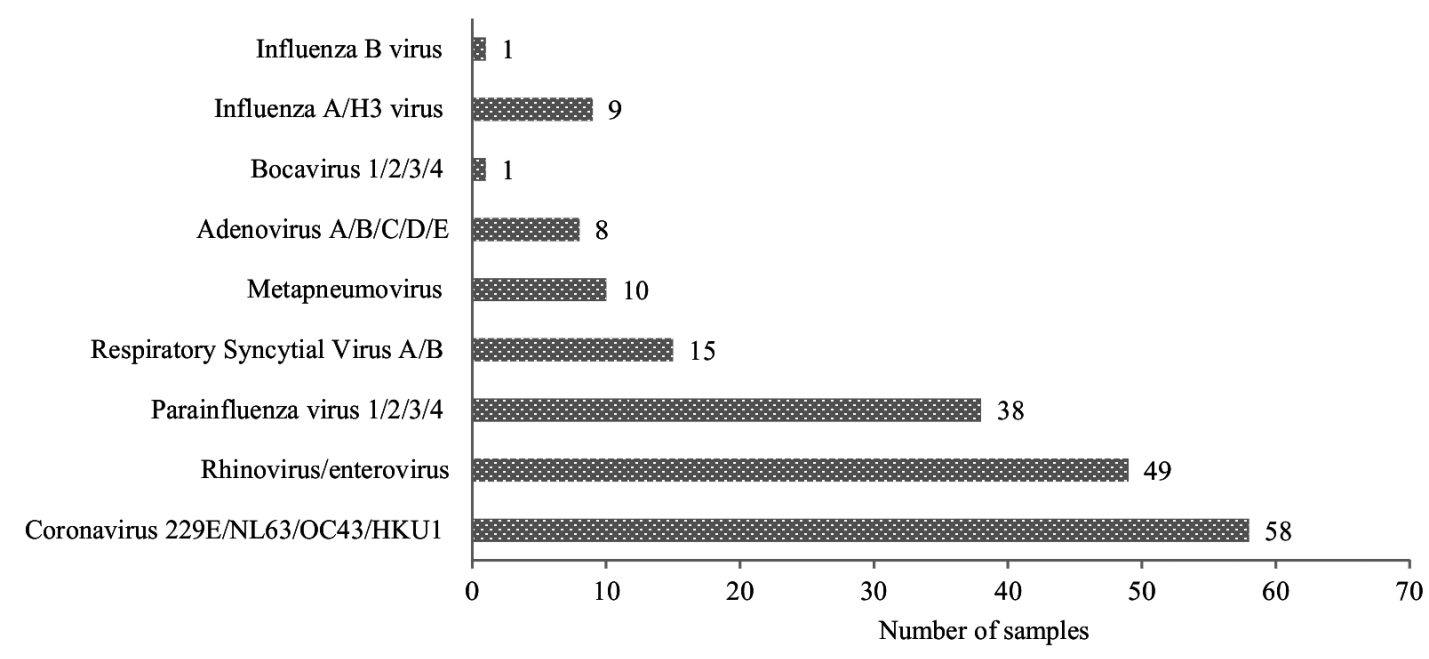

Figure 2. Distribution of viral pathogenic agents in positive samples (single and co-infections)

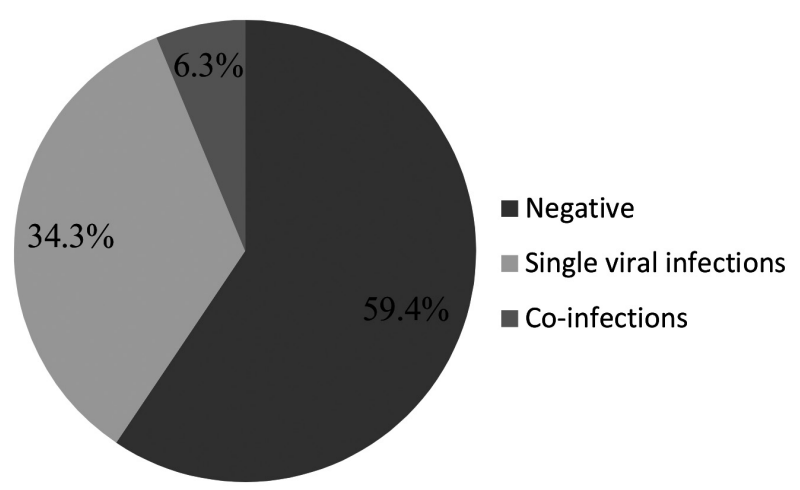

Figure 1. Percentage of viral infections including co-infections

\section{Viral etiology of respiratory infections}

A total of 399 samples, including 16 samples from KFOR, were analyzed by reverse transcription real-time PCR. One-hundred and sixty-two swabs were positive for respiratory viruses. One-hundred and thirty-seven samples were positive for single viral infections. However, viral co-infections (25 cases) were noticed as well (Fig. 1). Among them, 21 cases were positive for two viral agents, in four samples three viral agents were identified. Notably, 28 samples were positive for viruses and pathogenic bacteria.

Influenza virus type A and type B were confirmed in 9 and 1 nasopharyngeal specimen, respectively, which amounts to $6 \%$ of samples $(95 \%$ confidence interval $\left[\mathrm{CI}_{95 \%}\right]$ : 2-10\%). Specific subtyping for influenza A was performed resulting in detection of influenza virus A/ $\mathrm{H} 3$ in all 9 swabs. Additionally, the following viruses were identified: coronavirus $(\mathrm{n}=58$, including 4 cases in $\mathrm{KFOR}, 36 \%, \mathrm{CI}_{95 \%}: 29-43 \%$ ), rhinovirus/enterovirus $\left(\mathrm{n}=49,30 \%, \mathrm{CI}_{95 \%}: 23-37 \%\right)$, parainfluenza virus $\left(\mathrm{n}=38,23 \%, \mathrm{CI}_{95 \%}: 17-30 \%\right)$, respiratory syncytial virus $\left(\mathrm{n}=15,9 \%, \mathrm{CI}_{95 \%}: 5-14 \%\right)$, metapneumovirus $(\mathrm{n}=10$, $\left.6 \%, \mathrm{CI}_{95 \%}: 2-10 \%\right)$, adenovirus ( $\left.\mathrm{n}=8,5 \%, \mathrm{CI}_{95 \%}: 2-8 \%\right)$, and one case of bocavirus (parvovirus) (Fig. 2).

The study population analyzed for viral infections comprised 206 men and 193 women. Viral genetic material was found in 78 and 84 specimens, respectively. Among women cases caused by parainfluenza viruses, 


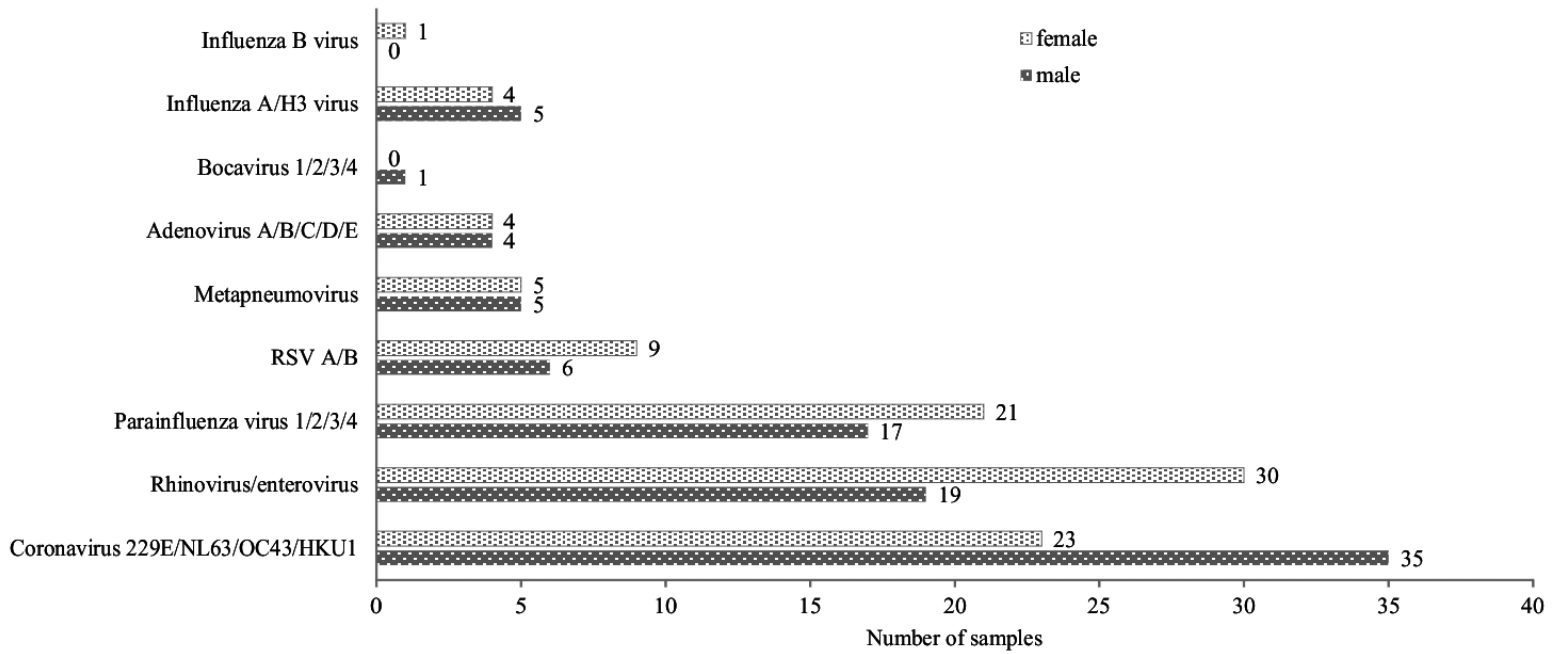

Figure 3. Gender distribution of respiratory virus infections

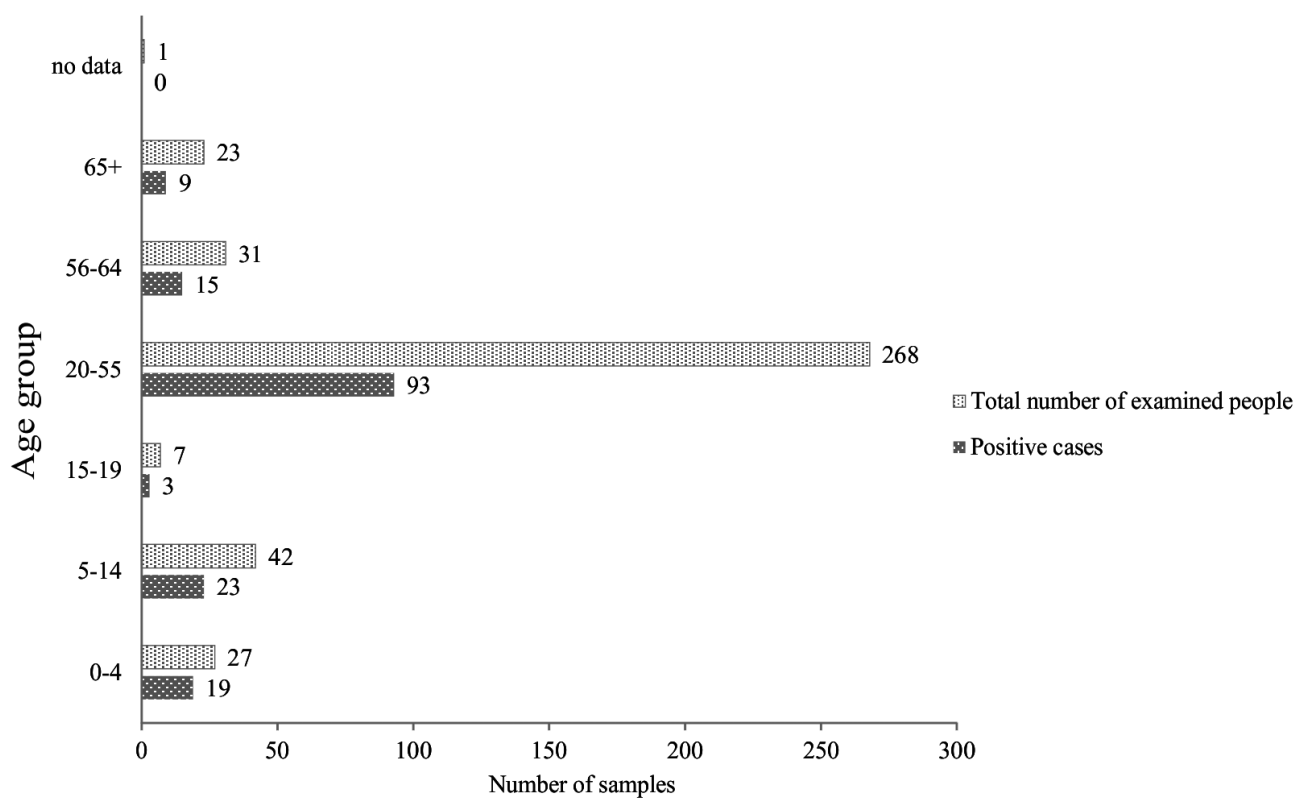

Figure 4. Prevalence of viral infections in age groups

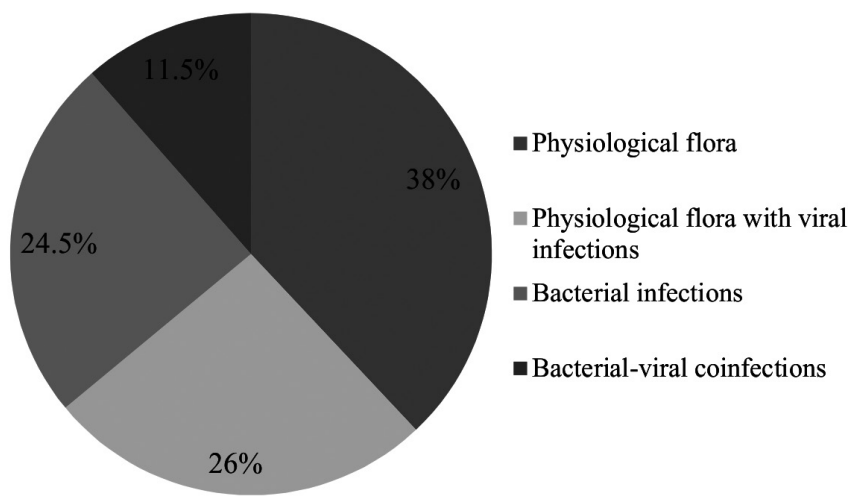

Figure 5. Percentage of bacterial infections including co-infections

rhinoviruses/enteroviruses and respiratory syncytial viruses were more common. Among men, coronavirus was the dominant cause. Similar numbers of women and men were infected by metapneumovirus and adenoviruses (Fig. 3).

The study population was grouped into 6 age intervals: children ( $0-4$ years), elementary school-age children (5-14 years), teenagers (15-19 years), working adults (20-55 years), retired (56-64 years) and elderly ( $\geq 65$ years). Children above 4 years old were the age group which was the most prone to viral respiratory infections. The next age groups were children at school age and retirees. The viral diseases were the least prevalent in the age group 20-55, including military personnel (Fig. 4).

\section{Bacterial etiology of respiratory infections}

Among the 249 swab samples which were analyzed by culturing method, in 61 cases bacterial infections of the 


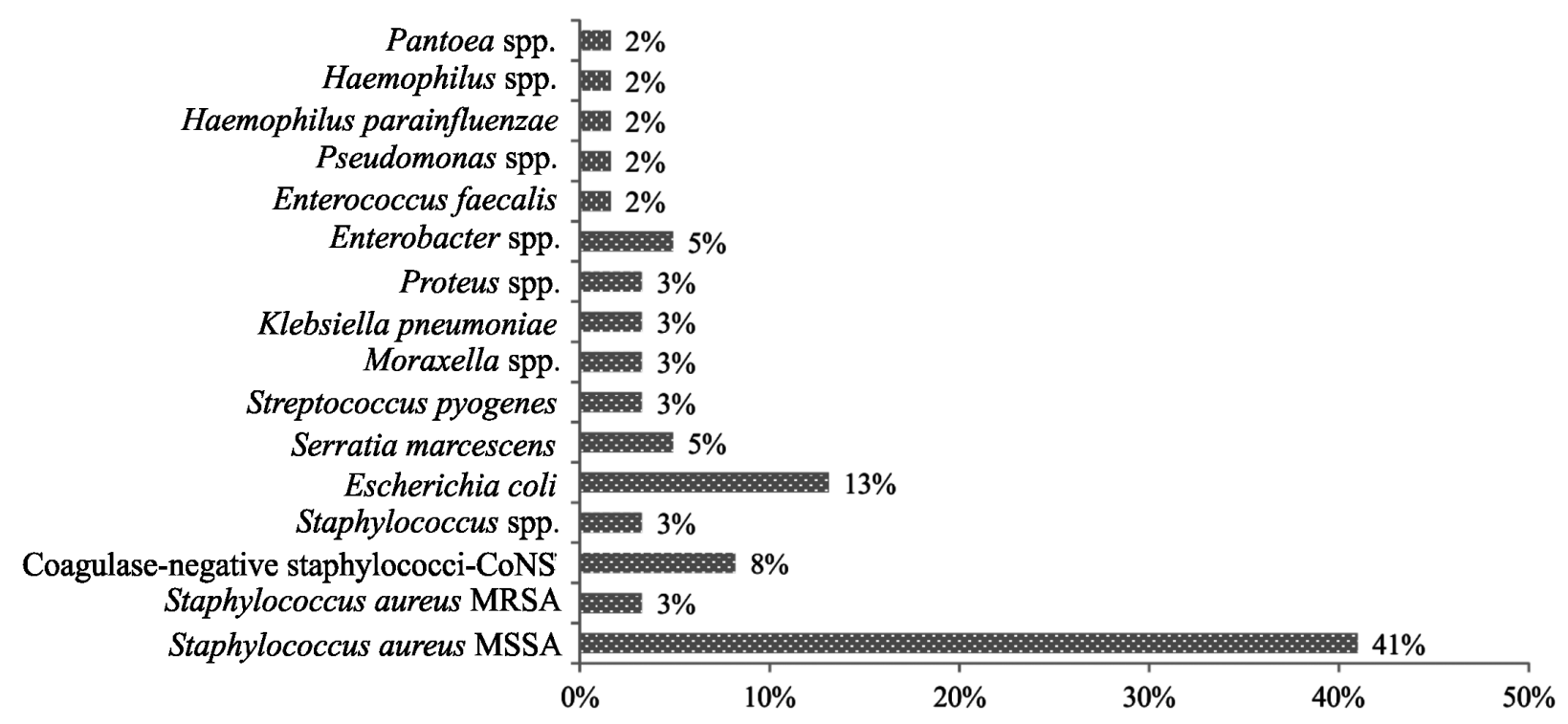

Figure 6. Percentage of bacterial agents in ILI symptomatic disease

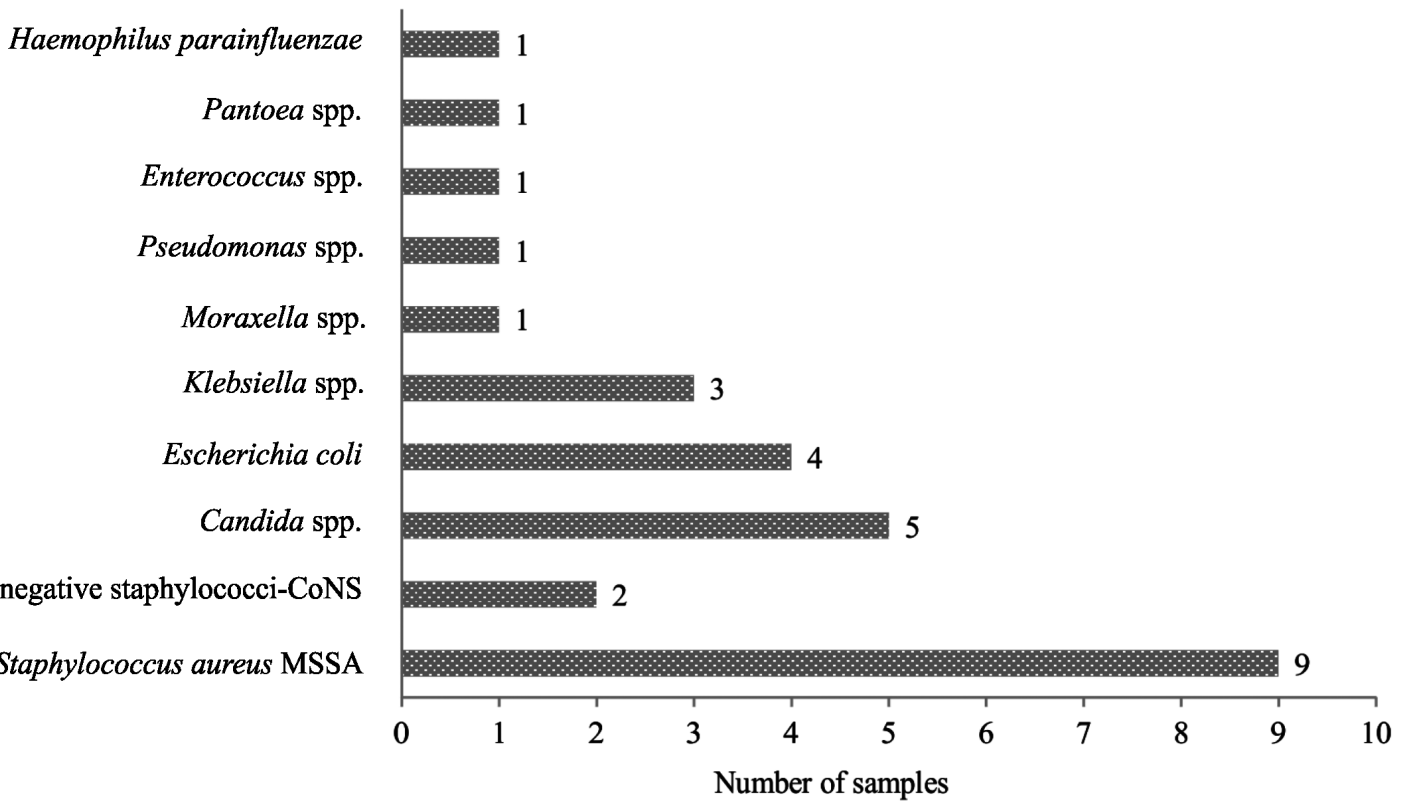

Figure 7. Percentage of bacterial/fungal etiologic agents in bacterial/fungal-viral co-infections

upper respiratory tract were identified. One-hundred and sixty remaining samples revealed the presence of bacterial physiological flora, of which 65 samples were additionally characterized by the presence of viral agents. Moreover, 28 samples demonstrated bacterial-viral coinfections (Fig. 5). Among all characterized bacterial agents, Staphylococcus aureus MSSA (methicillin-sensitive Staphylococcus aureus) was the dominant one (Figs. 6, 7).

Respiratory infections caused by bacterial pathogens were the most common in school-age children $(62 \%)$, followed by adults from 20 to 55 years old $(27.5 \%)$. No cases caused by bacterial pathogens were found among teenagers (Fig. 8).

\section{DISCUSSSION AND CONCLUSION}

Influenza like illnesses outbreaks may expand in high consequences scenarios, involving emerging of highly contagious and pathogenic influenza strains like the Spanish flu of 1918. Additionally, from the military perspective, some infectious diseases caused by biological warfare agents may resemble Influenza-like illnesses manifestation. Bearing this fact in mind, the effort to adapt existing national surveillance systems to near-real-time surveillance may be effective in recognizing an emergence of new respiratory pathogens or covert attacks involving biological agents, as well as improve the DoD's capabilities to monitor naturally occurring influenza. 


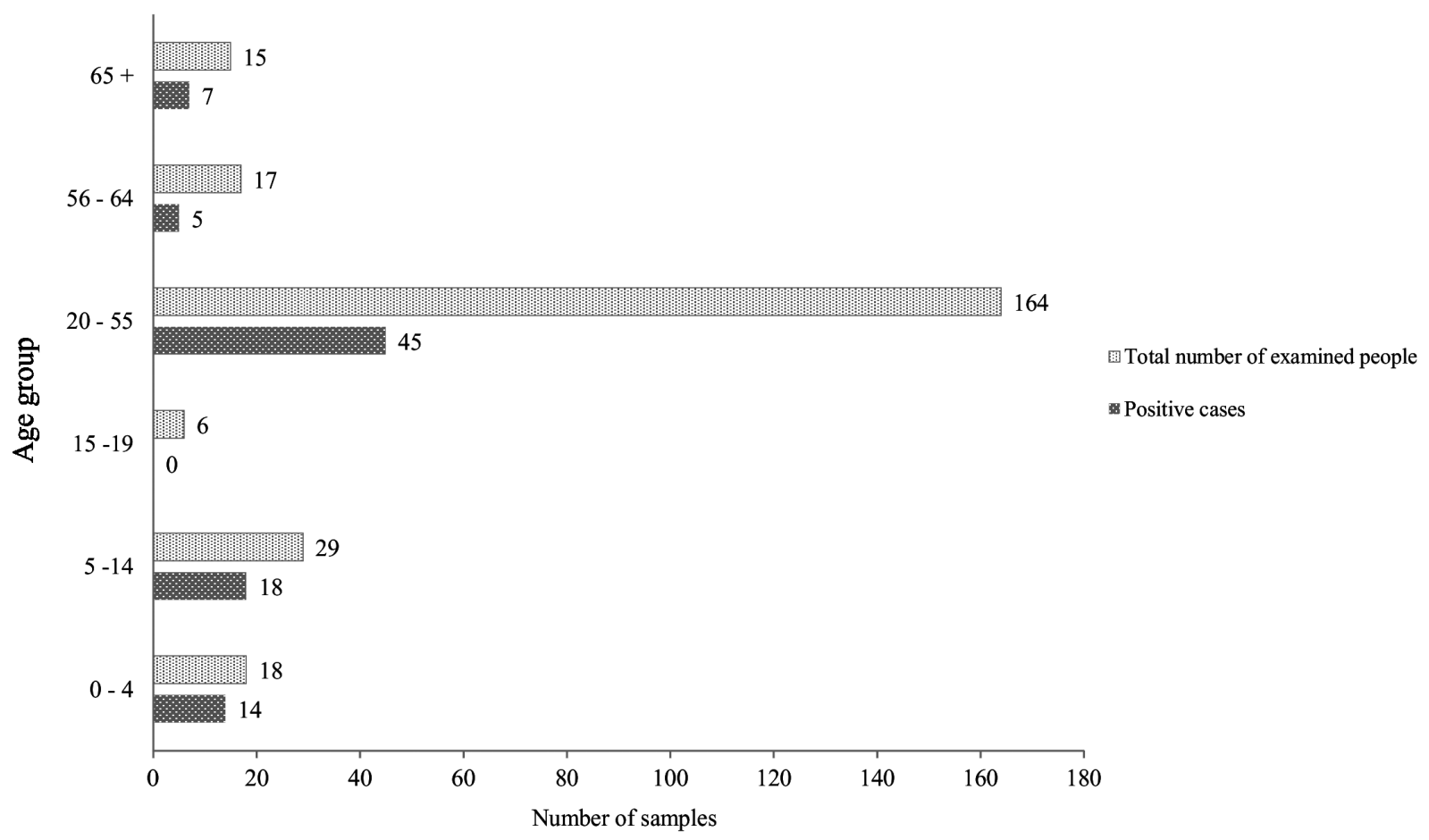

Figure 8. Prevalence of bacterial cases in age groups

As reported by the WHO European Region Office, "The 2011-2012 influenza season began late and was mild, with lower consultation rates of influenza-like illness/acute respiratory infection (ARI) and fewer virological influenza detections in most countries in the Region compared with previous years" (WHO 2012). In Poland, influenza and ILI incidence was 1,443.0 per 100,000 population in 2010 (EPIMELD-NIH 2010). Three-thousand and two influenza and 3,782 influenza-like illness infections per 100,000 population were reported during the epidemic seasons 2011 and 2012, respectively (EPIMELD-NIH 2012). Thus, these were the most common infectious diseases in Poland.

The study of a military population found similar levels of viral and bacterial infections. Respiratory tract infections caused by influenza virus in the study population accounted for only $6.2 \%$ of the examined cases. Thus, other respiratory viruses detected in RV Panel also appeared to be etiologic agents of respiratory infections. They all manifest similar symptoms, therefore the clinical course of a respiratory infection does not allow identifying clearly the species of the pathogen responsible for the infection.

Co-infections are an often-neglected phenomenon in the treatment of ILI cases - they could be viral-viral (Panasik \& Pancer, 2009) or viral-bacterial, and their true scale is still quite obscure (Falsey et al., 2013). They pose, however, a high risk of serious health consequences such as a more severe course of the disease and a consequent increased rate of hospitalization (Panasik \& Pancer, 2009). The treatment of co-infected patients can be much more complicated in terms of time and selection of drugs administered, acute manifestation of disease and complex laboratory analysis of clinical samples (Falsey et al., 2013).

Since the detection and identification of etiological agents of ILI cases can be time-consuming, novel methods have been developed recently. A rapid pro- gress has been observed in molecular multiplex identification of various pathogens (Lee et al., 2010; Huber et al., 2011; Nakauchi et al., 2011; Stefańska et al., 2012). Application of state-of- the-art methods based on twostep amplification with real-time nested detection allows rapid, sensitive and reliable detection of up to 12 most common viral pathogens. Our virological results seem to show typical trends similar to those observes by others (Paranhos-Baccala et al., 2008; Meerhoff et al., 2010; Lee et al., 2010). The scale of viral-viral co-infection in our study $(6.3 \%)$ was similar to those found by Lee and coworkers (2010) (6.8\%) or Paranhos-Baccala and coworkers (2008) (15.2\%). In contrast, Meerhoff and coworkers (2010) revealed 50\% incidence of viralviral co-infection. The frequency of viral-bacterial coinfections - $11.5 \%$ - was comparable to that reported by Falsey and coworkers (2013) - 18\%. Among the viral-bacterial co-infections the most common bacterial agent was Streptococcus aureus, as was also found by others (Chertow \& Memoli, 2013).

The presented data provide valuable information on influenza-like illness incidence among sentinel military populations at high risk. It allowed the identification of circulating viruses, including their variants or subtypes, and added some input to the debate on the modalities of empirical antiviral/antibacterial treatment and vaccine selection. The percentage of influenza-positive results was astonishingly low in this population in the second season after the 2009/2010 pandemic. This could have been caused by the late start of the influenza season and a selection advantage of other viruses in 2011/2012. Although vaccinepreventable influenza is the disease where prophylactic vaccination is most frequently encouraged, other viruses that may cause morbidity relevant to military operations deserve development of specific prophylactic measures, as shown by the ILI etiology in this study. 


\section{Acknowledgments}

We would like to thank Barbara Ciecierska and Dorota Sikorska for technical assistance in sample analysis.

\section{Financial support}

The research was funded by the Global Emerging Infections Surveillance and Response System.

\section{REFERENCES}

Bombardt Jr, JN \& Brown HE (2003) Potential influenza effects on military populations (No. IDA-P-3786). Institute for Defense Analyses, Alexandria,VA.

Chertow DS, Memoli MJ, (2013) Bacterial Coinfection in Influenza A Grand Rounds Review. JAMA 309: 275-282.

Cui S, Tian L, Peng X, Lu G, Shi W, Meng D, \& Wang Q (2012) Prevalence of seasonal influenza viruses and pandemic H1N1 Virus in Beijing from 2008 to 2012. Ann Lab Med 32: 455-456.

EPIMELD-NIH (2010) Occurrence of selected infectious diseases in Poland, from January 1st to December 31 st of 2010 in compared to period of 2009. National Institute of Public Health - National Institute of Hygiene (in Polish)

EPIMELD-NIH (2012) Occurrence of selected infectious diseases in Poland, from January 1st to December 31st of 2012 in compared to period of 2011. National Intitute of Public Health - National Institute of Hygiene (in Polish)

EUCAST (2012) European Committee on Antimicrobial Susceptibility Testing. Breakpoint tables for interpretation of MICs and zone diameters. Version 2.0, valid from 2012-01-01 (http://www.korld.edu.pl/pdf/ eucast/EUCAST breakpoints tlumaczenie v2-2012.pdf) (in Polish).

Falsey AR, Becker KL, Swinburne AJ, Nylen ES, Formica MA, Hennessey PA, Criddle MM, Peterson DR, Baran A, Walsh EE (2013)
Bacterial complications of respiratory tract viral illness: a comprehensive evaluation. I Infect Dis 208: 432-41.

Harrison TR, Adams RD, Bennett Jr, IL, Resnik, WH, Thorn GW, \& Wintrobe MM (1962) Principles of internal medicine. Acad Med 37: 1246.

Huber I, Campe H, Sebah D, Hartberger C, Konrad R, Bayer M, Busch U, Sing A (2011) A multiplex one-step real-time RT-PCR assay for influenza surveillance. Euro Surveill 16: 19798-19805.

Lee JH, Chun JK, Kim DS, Park Y, Choi JR, Kim HS (2010) Identification of adenovirus, influenza virus, parainfluenza virus, and respiratory syncytial virus by two kinds of multiplex polymerase chain reaction (PCR) and shell vial culture in pediatric patients with viral pneumonia. Yonsei Med J 51: 761-767.

Leo YS, Lye DC, Barkham T, Krishnan P, Seow E, Chow A (2010) Pandemic (H1N1) 2009 surveillance and prevalence of seasonal influenza, Singapore. Emerg Infect Dis 16: 103-105.

Meerhoff TJ, Houben ML, Coenjaerc FEJ, Kimpen JLL, Hoffland RW, Schellevis F, Bont LJ (2010) Detection of multiple respiratory pathogens during primary respiratory infection: nasal swab versus nosopharyngeal aspirate using real-time polymerase chain reaction. Eur J Clin Microbiol Infect Dis 29: 365-371.

Nakauchi M, Yasui Y, Miyoshi T, Minagawa H, Tanaka T, Tashiro M, Kageyama T (2011) One-step real-time reverse transcription-PCR assays for detecting and subtyping pandemic influenza $\mathrm{A} / \mathrm{H} 1 \mathrm{~N} 1$ 2009, seasonal influenza A/H1N1, and seasonal influenza A/H3N2 viruses. J Virol Methods 171: 156-162.

Panasik A, Pancer K (2009) Human metapneumovirus infection (HMPV) in children. Pryegl Epidemiol 63: 371-376 (in Polish).

Paranhos-Baccalà G, Komurian-Pradel F, Richard N, Vernet G, Lina B, Floret D (2008) Mixed respiratory virus infections. J Clin Virol 43: 407-410.

Stefańska I, Romanowska M, Brydak LB (2012) Methods of detection of selected respiratory viruses. Post Hig Med Dosw 66: 452-460 (in Polish).

WHO (2012) Summary of the 2011-2012 influenza season in the WHO European region, http://www.euro.who.int. 